\title{
Dificuldades encontradas durante o processo de legalização das agroindústrias no município de Santana do Livramento (RS)
}

\begin{tabular}{|c|c|}
\hline Andressa Arigony Aguirre & $\begin{array}{l}\text { Universidade Estadual do Rio Grande do Sul (UERGS). Unidade em } \\
\text { Santana do Livramento. }\end{array}$ \\
\hline Alessandra Machado Martins & $\begin{array}{l}\text { E-mails: dessah.aguirre@gmail.com } \\
\text { alemachadomartins@hotmail.com }\end{array}$ \\
\hline Leonardo de Melo Menezes & leonardo-menezes@uergs.edu.br \\
\hline
\end{tabular}

Recebido: 12 fev. 2018. Revisado: 06 abr. 2018. Aceito: 12 abr. 2018.

DOI: http://dx.doi.org/10.21674/2448-0479.41.136-151

\begin{abstract}
Resumo
O presente estudo tem como linha de pesquisa o desenvolvimento territorial através da importância da consolidação das agroindústrias locais para o desenvolvimento dos municípios. A existência de agroindústrias permite maior agregação de produtos tidos como commodities, e representam um importante papel na economia das cidades, contribuindo tanto para a produção de alimentos, quanto para a geração de renda. Assim, o objetivo deste estudo foi investigar quais são os principais entraves para regularização de agroindústrias familiares. Nesse contexto, realizou-se uma pesquisa nas agroindústrias de Santana do Livramento - RS, com o objetivo de definir, sob a perspectiva dos proprietários, quais foram as principais dificuldades encontrados durante o processo de legalização. Para tanto, foram aplicados junto à 49 agroindústrias locais, um questionário contendo perguntas fechadas e abertas. O estudo apontou a falta de legislação especifica para agroindústrias de pequeno porte ou familiares, e a burocracia, como sendo alguns dos principais entraves enfrentados durante o processo de legalização.
\end{abstract}

Palavras-chave: Agricultura Familiar. Agroindustrialização. Formalização.

\section{Abstract \\ Difficulties founded during legalization of agroindustries in Santana do Livramento - RS}

The present study adopts as research line the territorial development through the importance of consolidating local agroindustries as a way to accelerate the municipalities' development. The existence of agroindustries allows greater aggregation of products considered as commodities, and play an important role in cities' economy, contributing both in food production and in income generation. The objective of this study was to investigate the main obstacles to family agroindustries regularization. In this context, a research was carried out in the agroindustries of Santana do Livramento (Rio Grande do Sul), in order to investigate, from the owners' perspective, the main difficulties faced during the legalization process. Therefore, they were applied a questionnaire containing closed and open questions to the 49 local agroindustries. The main results of this study indicate the lack of specific legislation for small or family agroindustries, and bureaucracy, as the most relevant obstacles faced during the legalization process.

Keywords: Family Farming. Agroindustrialization. Formalization. 


\section{Introdução}

As agroindústrias desempenham um importante papel na economia dos municípios, principalmente no que se refere à produção de alimentos e a geração de renda. A produção de alimentos através da agroindustrialização aparece, muitas vezes, como fonte complementar de renda, porém, em outros casos, também pode representar a principal fonte de recursos das famílias. Além disso, o incentivo à produção agroindustrial também desempenha grande influência para a permanência dos agricultores, principalmente os mais jovens, no meio rural. Assim, contribui para diminuir o êxodo rural e todas as implicações que este causa, uma vez que grande parte dos agricultores que deixam o meio rural a fim de "tentar a vida na cidade", acaba ficando à margem da sociedade. A formalização das agroindústrias também representa um grande aliado para o controle e a qualidade na transformação de matérias primas, garantindo assim, a segurança alimentar.

Nesse sentindo, o presente estudo aborda a temática das agroindústrias locais, e tem como problema de pesquisa central quais os principais entraves e dificuldades enfrentados na formalização das agroindústrias da cidade de Santana do Livramento - RS. Sendo assim, o objetivo geral proposto neste artigo comtempla a investigação e identificação dos principais entraves encontrados durante o processo de legalização das agroindústrias do município, voltando o olhar, principalmente, sob como a legislação vigente atual influencia neste processo. Como objetivos específicos, aparece a verificação das dificuldades enfrentadas para manter as agroindústrias em funcionamento, e quais as politicas públicas e medidas de apoio, esperadas pelos proprietários, a fim de fomentar e facilitar a legalização das mesmas.

\section{Referencial Teórico}

De acordo com a abordagem territorial defendida por Schneider (2004), a visão do território surge como uma unidade de referencia para a atuação do Estado e a regulamentação das políticas públicas, tendo em vista a necessidade de superar as mazelas sociais que permeiam o cotidiano, como a pobreza, o desemprego e a violência. É neste sentido que cresce a importância das prefeituras locais e atores da sociedade civil, descentralizando as politicas publicas, e valorizando a participação das ONGs e os próprios beneficiários neste processo. Estas ações de intervenção decorrentes deste deslocamento, é que passaram a se denominar desenvolvimento territorial.

Os sistemas de produção locais, decorrentes dos processos endógenos de desenvolvimento territorial, permitem uma articulação das novas formas de produção com o modo de vida local, pois operam com base em relações de trabalho peculiares, que estão relacionas aos ambientes social e econômico (SCHNEIDER, 2004). Para este mesmo autor, a criação de programas e ações de desenvolvimento territorial rural, são capazes de gerar transformações, ampliando o conceito rural para além da agricultura e valorizando a heterogeneidade dos territórios, a sua capacidade endógena de desenvolver iniciativas assentadas na sua identidade socialmente legitimada.

Um novo olhar do território, com o enfoque no fortalecimento do capital social ali presente, tem o poder de revelar novos potenciais. As populações que vivem na zona rural têm a capacidade de tornarem-se protagonistas centrais da construção destes novos territórios. Isto se justifica até quando analisado o próprio crescimento urbano recente, onde, cada vez mais, observamos uma crescente demanda por novos produtos e novos serviços advindos do meio rural (ABRAMOVAY, 2000) 
Abramovay (2000) destaca o potencial que a valorização das características territoriais peculiares a cada região do país pode trazer ao desenvolvimento. As politicas e proposição em torno do território aparecem como fomento às novas configurações entre o campo e a cidade. Nesse contexto, o meio rural aparece como alternativa capaz de propiciar oportunidades, gerar renda, e diminuir o êxodo rural. É neste sentindo que a agroindústria aparece e consolida-se como alternativa a muitas famílias.

A agroindustrialização de alimentos em pequena escala e oriunda da agricultura familiar, intensificou-se a partir da década de 1990. Neste momento, um contingente de agricultores familiares, viu-se excluído perante a nova conjuntura, onde, até então, o mercado de produtos agropecuários era dominado pelos grandes complexos agroindustriais, fomentados desde meados da década de 1970 , por politicas públicas, e incentivos aos pacotes tecnológicos advindos da Revolução Verde. Desde aí, a complexidade do processo de transformação e problemática rural continuam em pauta, pois apesar dos esforços e estratégias convencionais do desenvolvimento rural, a produção verticalizada sempre foi privilegiada em detrimento da distribuição e elevação da renda das famílias que estavam nas ocupações agrícolas. A partir deste momento, tem início um conjunto de atividades não-agrícolas, que tem por objetivo propiciar a expansão de novas formas de ocupação e emprego para as famílias rurais (AMORIM e STADUTO, 2008).

Nessa perspectiva, a agroindustrialização representa um importante instrumento de desenvolvimento da agricultura familiar. Prezotto (2002) destaca que a cidadania representa um importante instrumento para a mudança do atual modelo de desenvolvimento. Para isso, a base da pequena agroindústria não deve levar em consideração apenas o caráter econômico, sob pena de repetir o modelo convencional, que gerava/gera a exclusão. Para o autor, a pequena agroindústria familiar, através da sua pluralidade, tem a capacidade não só de gerar renda direta e indiretamente, mas também, de contribuir para a inclusão social e econômica das pessoas que deste meio dependem.

De acordo com Sulbacher e David (2009) a agroindústria familiar rural pode ser fomentada como importante estratégia para reverter as consequências socioeconômicas da modernização conservadora na agricultura. Os autores ressaltam a importância da participação dos agricultores familiares neste processo, pois através da agroindustrialização, a história e a cultura destes passa a ser valorizada. Nesse sentindo, aparecem as políticas públicas, que tem por objetivo retirar da informalidade a produção artesanal dos alimentos, usando-se da segurança alimentar. Porém, assim como a legislação tem a capacidade de dar maior qualidade à produção, também pode constituir um empecilho para que a atividade se desenvolva na pequena propriedade rural dentro das exigências legais.

A questão de qualidade dos produtos, ainda é um tema que merece ser melhor desbravado e debatido, pois possui múltiplas dimensões, não existindo um consenso entre agricultores, consumidores, gestores públicos e técnico (SCARABELOT e SCHNEIDER, 2012). Scarabelot e Schneider (2012) definiram o impasse existente entre a definição de qualidade aceita para fins de legislação e o entendimento dos produtores e consumidores:

Para a grande maioria, a qualidade ainda é aquela que deriva das normativas governamentais, cuja maior preocupação é com a inocuidade relativa às questões físicas e biológicas, o que acaba por conferir pouca atenção para as questões de contaminação química ou aspectos imateriais. A discussão da qualidade associada às questões étnica e cultural, através de produtos típicos é tema que reclama uma discussão coletiva, que envolve tantos produtores como os consumidores, além dos órgãos de regulação. (SCARABELOT e SCHNEIDER, 2012, p.126) 
Para melhor abordar a temática da agroindustrialização, torna-se necessário trazer o conceito de agroindústria. Deste modo, a definição mais ampla de agroindústria engloba o complexo agroindustrial como um todo, ou seja, todos os agentes que fazem parte do segmento de insumos e fatores de produção (antes da porteira), da produção propriamente dita (dentro da porteira), do processamento e da transformação até a distribuição e o consumo (depois da porteira).

Tendo em vista uma perspectiva mais restrita, a agroindústria representa basicamente as indústrias que se dedicam à transformação e ao processamento de matérias-primas agropecuárias, podendo ser de origem animal ou vegetal. Tais matérias-primas que são transformadas e preservadas através de alterações físico-químicas, caracterizam-se por apresentar grande variabilidade (qualitativa e quantitativa), diferentes graus de perecibilidade e sazonalidade.

Sacco dos Anjos, Caldas e Oliveira (2015), identificaram algumas políticas públicas de fomento à agroindustrialização que foram relevantes no Estado do Rio Grande. No trabalho de campo realizado pelos autores, destacam-se situações em que houve o acesso ao Programa Nacional de Fortalecimento da Agricultura Familiar (doravante Pronaf), na modalidade Agroindústria, e o Programa de Agroindustrialização Familiar, mais conhecido como "Sabor Gaúcho" (programa concebido durante - Governo de Olívio Dutra que não teve continuidade nos governos subsequentes). Para os autores, estes programas tiveram como objetivo alcançar agricultores familiares que possuíssem capacidade, interesse de aprimoramento e qualificação profissional. Os autores salientaram o difícil acesso a estes programas, uma vez que os riscos implicados nesses processos justificavam a criteriosa escolha dos beneficiários, pois estes aspectos são considerados decisivos para o êxito ou o fracasso destes pequenos empreendimentos.

O estado do Rio Grande do Sul, desde 2012, possui uma legislação específica sobre a agroindústria familiar rural, chamada de PEAF (Programa Estadual da Agroindústria Familiar), que trata-se de um programa que visa principalmente, a implantação e a legalização de agroindústrias familiares e agroindústrias familiares de pequeno porte de processamento artesanal, com vista ao desenvolvimento rural sustentável. A legalização das agroindústrias representa a garantia da procedência e da qualidade do produto, e traz consigo uma série de normas, elaboradas a fim de atender às exigências dos órgãos públicos. Mas para isto, é necessário compreender e dar condições às agroindústrias para que estas consigam adequar-se a tal legislação, sendo fundamental entender quais as principais dificuldades existentes neste processo (FERNANDES e ENGEL, 2016).

Nesse contexto, Fernandes e Engel (2016) questionam-se: que vantagens e desvantagens possui o agricultor familiar com a legalização de sua agroindústria? Para elucidar essa questão, os autores analisaram a realidade pós-legalização de um ramo especifico de agroindústrias familiares rurais, que retrataram como maior desvantagem pós- legalização, a inclusão de gastos com taxas e impostos, uma vez que estes custos não ocorrem quando se atua na informalidade. Adequar-se à legislação, principalmente a sanitária, também aparece no estudo como grande dificuldade durante o processo, pois demanda mais informações, instruções, cursos e palestras aos gestores das agroindústrias e recursos financeiros para construção ou reforma das suas instalações. Ao analisarem as vantagens pós-legalização, os autores identificaram a possibilidade de comercializar produtos via programas estaduais, como principal vantagem. Além disso, o estudo também ressaltou que após a legalização, houve um aumento da clientela e, também, do volume de produtos comercializados.

De acordo com estudos realizados por Nichele e Waquil (2011), para alguns agricultores, a legislação imposta pode inviabilizar a produção e prejudicar o bom funcionamento do mercado agroindustrial familiar rural, uma vez estas normas não correspondem à demanda dos agricultores e consumidores. Mudanças na estrutura física e nos processos de produção, além de representarem um 
elevado investimento, podem acarretar na diminuição das vendas, pois o produto perde seu caráter artesanal.

Os principais órgãos responsáveis por fomentar programas públicos são as Prefeituras Municipais, Secretarias Municipais de Agricultura (SMA), serviços de assistência técnica e extensão rural (EMATER/RS). Dentre as estruturas locais, cabe salientar a importância do Sistema de Inspeção Municipal (SIM), que está presente em 290 municípios do Rio Grande do Sul (GAZOLLA, 2014). Atualmente, o município de Santana do Livramento, onde o presente estudo desenvolveu-se, possui SIM instalado e em funcionamento.

Ocorre que os órgãos responsáveis pela inspeção priorizam as estruturas físicas agroindustriais, em detrimento do processo de produção em si, que envolve, por exemplo, o cuidado com a higiene, qualidade dos alimentos e aplicação das BPF (boas práticas de fabricação) (GAZOLLA, 2014). De acordo com estudo realizado por Gazolla (2014), os investimentos com planta e equipamentos representam os maiores custos fixos das agroindústrias. $O$ estudo também contesta a não existência de regras diferentes entre, o que o autor denomina de "dois mundos" do processamento de alimentos - o industrial e artesanal, e destaca a necessidade de criação de regras próprias para o segmento artesanal e familiar das agroindústrias.

\section{Materiais e Métodos}

O presente trabalho representa uma pesquisa de natureza básica, com abordagem qualitativa e quantitativa na qual realizou-se uma pesquisa descritiva e explicativa acerca do tema proposto. Para tanto, foi realizado um estudo de caso durante o segundo semestre do ano de 2016, nas agroindústrias legalizadas do município de Santana do Livramento, localizado no estado do Rio Grande do Sul.

De acordo com o SIM (Serviço de Inspeção Municipal), a cidade conta com 61 agroindústrias formalizadas, sendo todas estas de Origem Animal, as quais distribuem-se nas zonas urbanas e rurais do município. Foram utilizadas para esta pesquisa dados primários, no qual foram coletados através da aplicação em 49 agroindústrias legalizadas, com questões fechadas (múltipla escolha) e questões abertas. O tratamento dos resultados foi realizado através da tabulação em planilhas eletrônicas (Excel) e elaboração de tabelas com o percentual das perguntas fechadas, e a análise e problematização do discurso das perguntas abertas.

\section{Resultados}

Para este estudo foram aplicados questionários em um universo de 49 agroindústrias legalizadas. Deste total, obteve-se resposta de 39. Dentre as agroindústrias que retornaram o questionário, 15 agroindústrias autodeclararam-se familiares, e 24 autodeclararam-se empresariais, sendo que, como já mencionado anteriormente, a matéria prima utilizada em todas é exclusivamente de origem animal. Dentre estas agroindústrias, 39 afirmaram ser inspecionadas pelo SIM (serviço de inspeção municipal), e apenas 2 pelo CISPOA. Das 39 agroindústrias questionadas, 34 (87\%) alegaram comercializar a produção apenas no comercio local, e apenas $5(12 \%)$ em outros municípios. Deste universo de agroindústrias que fizeram parte do estudo, $23(59 \%)$ manifestaram possuir 
interesse em ampliar a abrangência do mercado consumidor, sendo que 16 (41\%) disseram não possuir interesse na ampliação da comercialização no momento da pesquisa.

O questionário aplicado aos proprietários das agroindústrias foi dividido em dois módulos. A primeira parte remete às perguntas fechadas e de múltipla escolha, onde os responsáveis pelas agroindústrias foram indagados sobre as dificuldades e entraves enfrentados na etapa de legalização das agroindústrias. Para isto, foi solicitado que classificassem as dificuldades e entraves apresentados de acordo com graus de dificuldade que variavam de 1 a 4 . O grau 1 representa um grau de dificuldade muito baixo, o grau 2 um grau de dificuldade relativamente baixo, o grau 3 um grau de dificuldade alto e grau 4 um grau de dificuldade muito alto. Na sequencia, o questionário apresentava perguntas abertas, nas quais os proprietários das agroindústrias tiveram a oportunidade de discursar, expor seus pontos de vista, e também nos colocar a par da realidade em vivem.

\section{Resultados das perguntas de múltipla escolha}

$\mathrm{Na}$ Tabela 1 estão apresentados os resultados obtidos e agrupados das 39 agroindústrias entrevistadas. Na primeira coluna da Tabela 1, foi apresentado aos representantes das agroindústrias entraves e dificuldades encontradas normalmente durante o processo de legalização, e nas demais colunas, solicitou-se a classificação das dificuldades atribuindo-lhes notas de 1 a 4 . Os resultados demonstram que de acordo com $41 \%$ das agroindústrias questionadas, o grau de dificuldade para a legalização referente aos investimentos com estrutura física foi considerado alto (grau 3). Quanto a liberação/expedição de certidão de uso/ocupação do solo expedida pelo município, grande maioria, sendo $36 \%$, classificaram como sendo grau 2 (baixo). Em relação à dificuldade referente ao registro da empresa na Junta Comercial, e Cadastro Nacional de Pessoas Jurídicas (CNPJ) na Receita Federal), $48 \%$ classificaram como grau 2 (baixo). Quanto a dificuldade para obtenção do Bloco de Produtor Rural, $46 \%$ classificaram dos entrevistados também classificou a dificuldade como sendo baixa (grau 2). Para o entrave referente a elaboração do projeto técnico, sanitário e ambiental $48 \%$ classificaram esta dificuldade como moderada (grau 2). Quanto a dificuldades para obtenção das licenças referentes ao licenciamento ambiental (obtenção da Licença Previa (LP), Licença de Instalação (LI), Licença de Operação (LO) ou Licença Única de Instalação e Operação - (LIO), grande maioria, ou seja, 46\% dos questionados responderam como sendo muito difícil (grau 4). Na questão que diz respeito ao registro dos produtos, $38 \%$ dos responsáveis pelas agroindústrias classificaram esta dificuldade como alta (grau 3).

Em relação ao Registro do Estabelecimento (em caso de agroindústria de produtos de origem animal e de bebidas) ou Alvará de Funcionamento (agroindústrias de origem vegetal), $53 \%$ dos entrevistados classificaram em grau 2 (baixo). Quanto a rotulagem e a padronização do produto, $58 \%$ declararam ter encontrado nesta etapa um grau de dificuldade baixo (grau 2). Já nos entraves referentes as despesas com profissionais (responsável técnico) e também nos entraves com despesas com licenças, alvarás e certidões, $46 \%$ dos questionados disseram ter considerado esta etapa como sendo classificada dentro de grau de dificuldade alto (grau 3). Quanto aos números referentes as dificuldades encontradas devido a falta de legislação específica para agroindústrias familiares ou de pequeno porte, a grande maioria dos entrevistados, ou seja, $69 \%$ classificaram a etapa como sendo de grau de dificuldade muito alto (grau 4). Outro grande entrave ou dificuldade observado, diz respeito a parte burocrática, onde $64 \%$ classificaram como sendo grau 4 (dificuldade muito alta) no momento da legalização. Já na dificuldade encontrada para a comercialização/escoamento da produção, $51 \%$ dos entrevistados classificaram este ponto como grau 2 (baixo). 
Tabela 1 - Resultado geral dos questionários agrupado de acordo com o grau de dificuldade informado pelos respondentes (em percentual, $n=39$ ).

\begin{tabular}{|c|c|c|c|c|}
\hline & $\begin{array}{c}\text { Grau } \\
1^{*}\end{array}$ & $\begin{array}{c}\text { Grau } \\
2^{\star *}\end{array}$ & $\begin{array}{c}\text { Grau } \\
3^{\star \star *}\end{array}$ & $\begin{array}{c}\text { Grau } \\
4^{* \star \star *}\end{array}$ \\
\hline $\begin{array}{l}\text { Quanto aos investimentos com estrutura física (edificação da } \\
\text { agroindústria) }\end{array}$ & 2,56 & 28,21 & 41,03 & 28,21 \\
\hline $\begin{array}{l}\text { Quanto liberação/expedição de Certidão de uso/ocupação do } \\
\text { solo expedida pelo município }\end{array}$ & 12,12 & 36,36 & 24,24 & 27,27 \\
\hline $\begin{array}{l}\text { Dificuldade quanto ao registro da empresa na Junta Comercial, e } \\
\text { Cadastro Nacional de Pessoas Jurídicas (CNPJ) na Receita } \\
\text { Federal }\end{array}$ & 31,43 & 48,57 & 17,14 & 2,86 \\
\hline Dificuldade para obtenção do Bloco de Produtor Rural & 33,33 & 46,67 & 13,33 & 6,67 \\
\hline Quanto à elaboração do projeto técnico, sanitário e ambiental & 12,82 & 20,51 & 48,72 & 17,95 \\
\hline $\begin{array}{l}\text { Quanto ao licenciamento ambiental (obtenção da Licença Previa } \\
\text { (LP), Licença de Instalação (LI), Licença de Operação (LO) ou } \\
\text { Licença Única de Instalação e Operação - LIO) }\end{array}$ & 10,26 & 20,51 & 23,08 & 46,15 \\
\hline Quanto ao registro dos produtos & 12,82 & 35,90 & 38,46 & 12,82 \\
\hline $\begin{array}{l}\text { Quanto ao Registro do Estabelecimento (em caso de } \\
\text { agroindústria de produtos de origem animal e de bebidas) ou } \\
\text { Alvará de Funcionamento (agroindústrias de origem vegetal) }\end{array}$ & 10,26 & 53,85 & 17,95 & 17,95 \\
\hline Quanto à rotulagem & 10,26 & 58,97 & 12,82 & 17,95 \\
\hline Quanto a padronização do produto & 15,38 & 58,97 & 17,95 & 7,69 \\
\hline Quanto a despesas com profissionais (responsável técnico) & 7,69 & 28,21 & 46,15 & 17,95 \\
\hline Quanto a despesas com licenças, alvarás, certidões & 2,56 & 25,64 & 46,15 & 25,64 \\
\hline $\begin{array}{l}\text { Quanto a falta de legislação específica para agroindústrias } \\
\text { familiares ou de pequeno porte }\end{array}$ & 3,03 & 18,18 & 9,09 & 69,70 \\
\hline Quanto à burocracia & 2,56 & 12,82 & 20,51 & 64,10 \\
\hline Quanto a comercialização/escoamento da produção & 17,95 & 51,28 & 23,08 & 7,69 \\
\hline
\end{tabular}

As Tabelas 2, 3 e 4, representam os mesmos resultados da Tabela 1, porém apresentados de forma estratificada, ou seja, para a quantificação dos dados destas tabelas, as agroindústrias entrevistadas foram agrupadas de acordo com as matérias primas utilizadas na sua produção. Isto se deu com o propósito de encontrar uma possível semelhança entre as respostas obtidas com relação aos entraves e dificuldades apresentados às agroindústrias no momento da legalização. Para tal, as agroindústrias foram divididas em três categorias: processadoras de carne e derivados, processadores de leite e derivados, e processadoras de mel.

$\mathrm{Na}$ tabela 2, podemos observar os resultados classificados de acordo o grau de dificuldade enfrentado no momento da legalização para as agroindústrias de carne e derivados, as quais representam 27, do total de 39 agroindústrias que foram alvo do estudo. Em relação aos investimentos com estrutura física (edificação da agroindústria), 37\% das agroindústrias responderam classificar este entrave como sendo grau 3 (difícil). Quanto liberação/expedição de certidão de uso/ocupação do solo expedida pelo município, 39\% responderam considerar esta dificuldade como grau 2 (baixo). Quanto ao registro da empresa na Junta Comercial, e Cadastro Nacional de Pessoas Jurídicas (CNPJ) na Receita Federal, 51\% dos entrevistados responderam considerar esta dificuldade como sendo baixa (grau 2). Durante o processo de obtenção do Bloco de Produtor Rural, $40 \%$ das agroindústrias classificaram esta dificuldade como sendo baixa (grau 2).

$\mathrm{Na}$ parte que diz respeito à elaboração do projeto técnico, sanitário e ambiental, a grande maioria, sendo $62 \%$, classificou o grau de dificuldade enfrentado como alto (grau 3). Em se tratando do 
licenciamento ambiental (obtenção da Licença Previa (LP), Licença de Instalação (LI), Licença de Operação (LO) ou Licença Única de Instalação e Operação - (LIO) 59\% dos questionários analisados demostraram ter encontrado uma grande dificuldade (grau 4) nesta etapa. Quanto ao registro dos produtos, $44 \%$ dos responsáveis pelas agroindústrias responderam classificar esta etapa do processo de legalização como sendo difícil (grau 3). Já em relação ao Registro do Estabelecimento (em caso de agroindústria de produtos de origem animal e de bebidas) ou Alvará de Funcionamento (agroindústrias de origem vegetal) $44 \%$ das respostas obtidas classificaram esta dificuldade como sendo grau 2 (baixo). Quanto a rotulagem e padronização do produto, a maioria dos entrevistados classificou esta dificuldade como baixa (grau 2), representando $55 \%$ e $66 \%$, respectivamente. Referente às despesas com profissionais (responsável técnico) e despesas com licenças, alvarás, certidões, ambos os entraves apresentados foram classificados como sendo difíceis (grau 3), com $44 \%$ e $40 \%$ dos votos, respectivamente.

Em relação à falta de legislação específica para agroindústrias familiares ou de pequeno porte e a burocracia, os resultados apresentados foram expressivos, representando $72 \%$ e $70 \%$, respectivamente, das agroindústrias que classificaram este entrave como grau 4 (muito alto). Por fim, na dificuldade referente à comercialização/escoamento da produção, $51 \%$ responderam considerar esta etapa apenas como grau 2 (grau de dificuldade baixo).

Tabela 2 - Resultado estratificado de acordo com o grau de dificuldade referente a carne e derivados (em percentual)

\begin{tabular}{|c|c|c|c|c|}
\hline & $\begin{array}{c}\text { Grau } \\
1^{*}\end{array}$ & $\begin{array}{c}\text { Grau } \\
2^{\star *}\end{array}$ & $\begin{array}{c}\text { Grau } \\
3^{* * *}\end{array}$ & $\begin{array}{l}\text { Grau } \\
4^{* * * *}\end{array}$ \\
\hline Quanto aos investimentos com estrutura física (edificação da agroindústria) & 3,70 & 29,63 & 37,04 & 29,63 \\
\hline $\begin{array}{l}\text { Quanto liberação/expedição de Certidão de uso/ocupação do solo expedida } \\
\text { pelo município }\end{array}$ & 8,70 & 39,13 & 30,43 & 21,74 \\
\hline $\begin{array}{l}\text { Dificuldade quanto ao registro da empresa na Junta Comercial, e Cadastro } \\
\text { Nacional de Pessoas Jurídicas (CNPJ) na Receita Federal }\end{array}$ & 33,33 & 51,85 & 14,81 & 0,00 \\
\hline Dificuldade para obtenção do Bloco de Produtor Rural & 20,00 & 40,00 & 20,00 & 20,00 \\
\hline Quanto à elaboração do projeto técnico, sanitário e ambiental & 7,41 & 14,81 & 62,96 & 14,81 \\
\hline $\begin{array}{l}\text { Quanto ao licenciamento ambiental (obtenção da Licença Previa (LP), } \\
\text { Licença de Instalação (LI), Licença de Operação (LO) ou Licença Única de } \\
\text { Instalação e Operação - LIO) }\end{array}$ & 7,41 & 14,81 & 18,52 & 59,26 \\
\hline Quanto ao registro dos produtos & 11,11 & 33,33 & 44,44 & 11,11 \\
\hline $\begin{array}{l}\text { Quanto ao Registro do Estabelecimento (em caso de agroindústria de } \\
\text { produtos de origem animal e de bebidas) ou Alvará de Funcionamento } \\
\text { (agroindústrias de origem vegetal) }\end{array}$ & 14,81 & 44,44 & 18,52 & 22,22 \\
\hline Quanto a rotulagem & 11,11 & 55,56 & 14,81 & 18,52 \\
\hline Quanto à padronização do produto & 22,22 & 66,67 & 7,41 & 3,70 \\
\hline Quanto a despesas com profissionais (responsável técnico) & 11,11 & 29,63 & 44,44 & 14,81 \\
\hline Quanto às despesas com licenças, alvarás, certidões & 0,00 & 29,63 & 40,74 & 29,63 \\
\hline $\begin{array}{l}\text { Quanto à falta de legislação específica para agroindústrias familiares ou de } \\
\text { pequeno porte }\end{array}$ & 4,55 & 13,64 & 9,09 & 72,73 \\
\hline Quanto à burocracia & 3,70 & 3,70 & 22,22 & 70,37 \\
\hline Quanto a comercialização/escoamento da produção & 25,93 & 51,85 & 14,81 & 7,41 \\
\hline
\end{tabular}

A tabela 3, representa os resultados apresentados pelas agroindústrias de leite e derivados e a classificação dada por estas, para as dificuldades enfrentadas durante o processo de legalização. A categoria leite e derivados representou 11 agroindústrias das 39 que fizeram parte deste estudo. Com relação aos investimentos com estrutura física, $45 \%$ das agroindústrias desta categoria consideraram esta etapa do processo de legalização como sendo de dificuldade alta (grau 3). Quanto a etapa de liberação/expedição de Certidão de uso/ocupação do solo expedida pelo município, $44 \%$ das agroindústrias classificaram como sendo muito difícil (grau 4). Em relação à dificuldade enfrentada quanto ao registro da empresa na Junta Comercial, e Cadastro Nacional de Pessoas Jurídicas (CNPJ) 
na Receita Federal, 42\% classificaram como sendo apenas grau 2 (baixo). Já para a dificuldade para obtenção do Bloco de Produtor Rural, houve um empate entre as respostas apresentadas pelas agroindústrias, sendo que $44 \%$ classificaram com grau 2 (baixo) e também $44 \%$ como grau 3 (alto). Quanto a elaboração do projeto técnico, sanitário e ambiental, $36 \%$ do total classificaram como considerando esta dificuldade de grau 2 (baixa). Em relação ao licenciamento ambiental (obtenção da Licença Previa (LP), Licença de Instalação (LI), Licença de Operação (LO) ou Licença Única de Instalação e Operação - (LIO), também foi observado um empate entre as respostas, sendo que $36 \%$ das agroindústrias consideraram como grau 2 (baixo) e $36 \%$ como grau 3 (alto) as dificuldades encontradas. Quanto ao registro dos produtos, $45 \%$ das respostas apresentadas classificaram este entrave como baixo (grau 2).

Para a dificuldade referente ao Registro do Estabelecimento (em caso de agroindústria de produtos de origem animal e de bebidas) ou Alvará de Funcionamento (agroindústrias de origem vegetal) e o entrave referente a rotulagem, $72 \%$ classificaram esta etapa apenas como grau 2 (baixa). Quanto a padronização do produto, a maioria dos proprietários de agroindústrias classificaram esta dificuldade como grau 2 (baixa). Nas despesas com profissionais (responsável técnico), e em relação às despesas com licenças, alvarás, certidões ambos os entraves foram classificaram como sendo de grau de dificuldade alto (grau 3), representando $45 \%$ e $54 \%$, respectivamente. Em se tratando da falta de legislação específica para agroindústrias familiares ou de pequeno porte, e a dificuldade encontrada com a burocracia, as agroindústrias de leite de derivados classificaram estes entraves como muito alto (grau 4), com $60 \%$ e $45 \%$ dos votos, respectivamente. Para finalizar, o resultado apresentado para o último entrave, que diz respeito à comercialização/escoamento da produção, grande maioria, ou seja, 54\% classificaram a dificuldade nesta etapa como grau 2 (baixa).

Tabela 3 - Resultado estratificado de acordo com o grau de dificuldade referente a leite e derivados (em percentual).

\begin{tabular}{|c|c|c|c|c|}
\hline & $\begin{array}{c}\text { Grau } \\
1^{*}\end{array}$ & $\begin{array}{c}\text { Grau } \\
2^{* *}\end{array}$ & $\begin{array}{c}\text { Grau } \\
3^{* * *}\end{array}$ & $\begin{array}{l}\text { Grau } \\
4^{* * * *}\end{array}$ \\
\hline Quanto aos investimentos com estrutura física (edificação da agroindústria) & 0,00 & 27,27 & 45,45 & 27,27 \\
\hline $\begin{array}{l}\text { Quanto liberação/expedição de Certidão de uso/ocupação do solo expedida } \\
\text { pelo município }\end{array}$ & 11,11 & 33,33 & 11,11 & 44,44 \\
\hline $\begin{array}{l}\text { Dificuldade quanto ao registro da empresa na Junta Comercial, e Cadastro } \\
\text { Nacional de Pessoas Jurídicas (CNPJ) na Receita Federal }\end{array}$ & 28,57 & 42,86 & 14,29 & 14,29 \\
\hline Dificuldade para obtenção do Bloco de Produtor Rural & 44,44 & 44,44 & 11,11 & 0,00 \\
\hline Quanto à elaboração do projeto técnico, sanitário e ambiental & 18,18 & 36,36 & 18,18 & 27,27 \\
\hline $\begin{array}{l}\text { Quanto ao licenciamento ambiental (obtenção da Licença Previa (LP), } \\
\text { Licença de Instalação (LI), Licença de Operação (LO) ou Licença Única de } \\
\text { Instalação e Operação - LIO) }\end{array}$ & 9,09 & 36,36 & 36,36 & 18,18 \\
\hline Quanto ao registro dos produtos & 18,18 & 45,45 & 18,18 & 18,18 \\
\hline $\begin{array}{l}\text { Quanto ao Registro do Estabelecimento (em caso de agroindústria de } \\
\text { produtos de origem animal e de bebidas) ou Alvará de Funcionamento } \\
\text { (agroindústrias de origem vegetal) }\end{array}$ & 0,00 & 72,73 & 18,18 & 9,09 \\
\hline Quanto à rotulagem & 9,09 & 72,73 & 9,09 & 9,09 \\
\hline Quanto à padronização do produto & 0,00 & 45,45 & 36,36 & 18,18 \\
\hline Quanto a despesas com profissionais (responsável técnico) & 0,00 & 27,27 & 45,45 & 27,27 \\
\hline Quanto às despesas com licenças, alvarás, certidões & 9,09 & 18,18 & 54,55 & 18,18 \\
\hline $\begin{array}{l}\text { Quanto à falta de legislação específica para agroindústrias familiares ou de } \\
\text { pequeno porte }\end{array}$ & 0,00 & 30,00 & 10,00 & 60,00 \\
\hline Quanto a burocracia & 0,00 & 36,36 & 18,18 & 45,45 \\
\hline Quanto à comercialização/escoamento da produção & 0,00 & 54,55 & 36,36 & 9,09 \\
\hline
\end{tabular}

A Tabela 4 traz os resultados encontrados na avaliação do questionário da categoria de agroindústrias processadoras de mel, a qual foi reapresentada por 1 (uma) agroindústria. Conforme observamos na Tabela 4, a agroindústria processadora de mel participante do estudo, considerou os 
investimentos com estrutura física (edificação da agroindústria) como representando uma alta dificuldade (grau 3) durante o processo da sua legalização. Em relação à liberação/expedição de Certidão de uso/ocupação do solo expedida pelo município, os proprietários da agroindústria classificaram como muito baixa (grau 1) esta dificuldade. Quanto ao registro da empresa na Junta Comercial, e Cadastro Nacional de Pessoas Jurídicas (CNPJ) na Receita Federal, o grau de dificuldade encontrado foi classificado como sendo alto (grau 3). Para a dificuldade encontrada durante a obtenção do Bloco de Produtor Rural, a agroindústria classificou esta etapa como muito baixa (grau 2). Quanto a elaboração do projeto técnico, sanitário e ambiental, e entrave referente ao licenciamento ambiental (obtenção da Licença Previa (LP), Licença de Instalação (LI), Licença de Operação (LO) ou Licença Única de Instalação e Operação - (LIO), ambos os níveis de dificuldade enfrentados para esta etapa foram classificados como muito baixos (grau 1).

Em relação ao registro dos produtos, a agroindústria disse ter considero este processo como dificuldade grau 3 (alta). Já para o registro do Estabelecimento (em caso de agroindústria de produtos de origem animal e de bebidas) ou Alvará de Funcionamento (agroindústrias de origem vegetal) esta dificuldade foi classificada como sendo baixa (grau 2). Já em relação à rotulagem, a agroindústria processadora de mel classificou este entrave como representando um alto grau de dificuldade (grau 4). Quanto a padronização do produto, despesas com profissionais (responsável técnico), e o entrave referente às despesas com licenças, alvarás, certidões, o grau de dificuldade encontrado foi alto (grau 3). Os dois entraves que dizem respeito a falta de legislação específica para agroindústrias familiares ou de pequeno porte, e a burocracia, foram considerados muito altos (grau 4), sendo que a dificuldade encontrada referente a comercialização/escoamento da produção foi considerada alta (grau 3).

Tabela 4 - Resultado estratificado de acordo com o grau de dificuldade referente a mel (em percentual)

\begin{tabular}{|c|c|c|c|c|}
\hline & $\begin{array}{c}\text { Grau } \\
1^{*}\end{array}$ & $\begin{array}{c}\text { Grau } \\
2^{* *}\end{array}$ & $\begin{array}{l}\text { Grau } \\
3^{* * *}\end{array}$ & $\begin{array}{l}\text { Grau } \\
4^{* * * *}\end{array}$ \\
\hline $\begin{array}{l}\text { Quanto aos investimentos com estrutura física (edificação da } \\
\text { agroindústria) }\end{array}$ & 0,00 & 0,00 & 100,00 & 0,00 \\
\hline $\begin{array}{l}\text { Quanto liberação/expedição de Certidão de uso/ocupação do solo } \\
\text { expedida pelo município }\end{array}$ & 100,00 & 0,00 & 0,00 & 0,00 \\
\hline $\begin{array}{l}\text { Dificuldade quanto ao registro da empresa na Junta Comercial, e } \\
\text { Cadastro Nacional de Pessoas Jurídicas (CNPJ) na Receita Federal) }\end{array}$ & 0,00 & 0,00 & 100,00 & 0,00 \\
\hline Dificuldade para obtenção do Bloco de Produtor Rural & 0,00 & 100,00 & 0,00 & 0,00 \\
\hline Quanto à elaboração do projeto técnico, sanitário e ambiental & 100,00 & 0,00 & 0,00 & 0,00 \\
\hline $\begin{array}{l}\text { Quanto ao licenciamento ambiental (obtenção da Licença Previa (LP), } \\
\text { Licença de Instalação (LI), Licença de Operação (LO) ou Licença Única } \\
\text { de Instalação e Operação - LIO) }\end{array}$ & 100,00 & 0,00 & 0,00 & 0,00 \\
\hline Quanto ao registro dos produtos & 0,00 & 0,00 & 100,00 & 0,00 \\
\hline $\begin{array}{l}\text { Quanto ao Registro do Estabelecimento (em caso de agroindústria de } \\
\text { produtos de origem animal e de bebidas) ou Alvará de Funcionamento } \\
\text { (agroindústrias de origem vegetal) }\end{array}$ & 0,00 & 100,00 & 0,00 & 0,00 \\
\hline Quanto à rotulagem & 0,00 & 0,00 & 0,00 & 100,00 \\
\hline Quanto à padronização do produto & 0,00 & 0,00 & 100,00 & 0,00 \\
\hline Quanto a despesas com profissionais (responsável técnico) & 0,00 & 0,00 & 100,00 & 0,00 \\
\hline Quanto a despesas com licenças, alvarás, certidões & 0,00 & 0,00 & 100,00 & 0,00 \\
\hline $\begin{array}{l}\text { Quanto à falta de legislação específica para agroindústrias familiares ou } \\
\text { de pequeno porte }\end{array}$ & 0,00 & 0,00 & 0,00 & 100,00 \\
\hline Quanto à burocracia & 0,00 & 0,00 & 0,00 & 100,00 \\
\hline Quanto à comercialização/escoamento da produção & 0,00 & 0,00 & 100,00 & 0,00 \\
\hline
\end{tabular}

Para finalizar o tratamento dos dados referente as perguntas de múltipla escolha, a Tabela 5 demonstra a média ponderada geral encontrada após a análise dos resultados dos questionários de todas as agroindústrias. Para isto, as dificuldades e entraves foram elencadas e organizadas de 
acordo com a perspectiva das agroindústrias sob quais os graus de dificuldades foram considerados mais altos durante o processo de legalização.

Como podemos observar, a Tabela 5 demonstra o alto grau de dificuldade apresentado pelas agroindústrias, principalmente referente a burocracia e a falta de legislação específica para agroindústrias familiares ou de pequeno porte, os quais representaram $86 \%$ das respostas. $O$ licenciamento ambiental (obtenção da Licença Previa (LP), Licença de Instalação (LI), Licença de Operação (LO) ou Licença Única de Instalação e Operação - (LIO), representou 76\% da dificuldade encontrada durante o processo de legalização. Os investimentos com estrutura física (edificação da agroindústria), as despesas com licenças, alvarás, certidões, aparecem em seguida na tabela, representando $73 \%$ das maiores dificuldades encontradas. Os entraves encontrados com despesas com profissionais (responsável técnico), a elaboração do projeto técnico, sanitário e ambiental, e a liberação/expedição de Certidão de uso/ocupação do solo expedida pelo município, representaram $68 \%, 67 \%$ e $66 \%$ das respostas dos entrevistados.

Em seguida aparecem as dificuldades referente ao registro dos produtos $(60 \%)$, registro do Estabelecimento (em caso de agroindústria de produtos de origem animal e de bebidas) ou Alvará de Funcionamento (agroindústrias de origem vegetal) (60\%), e a rotulagem (59\%). Classificados como entraves um pouco menos expressivos no momento da legalização, aparecem a comercialização/escoamento da produção (55\%), a dificuldade na padronização do produto (54\%), a dificuldade referente a obtenção do Bloco de Produtor Rural (48\%), e a dificuldade quanto ao registro da empresa na Junta Comercial, e Cadastro Nacional de Pessoas Jurídicas (CNPJ) na Receita Federal que representou apenas $47 \%$ das respostas dos questionários obtidos.

Tabela 5 - Média ponderada geral das dificuldades e entraves de acordo com os questionários respondidos (resultados classificados do maior para o menor, em percentual)

\begin{tabular}{lc}
\hline Problema apontado & $\%$ \\
\hline Quanto à burocracia & 86,54 \\
Quanto à falta de legislação específica para agroindústrias familiares ou de pequeno porte & 86,36 \\
\hline Quanto ao licenciamento ambiental (obtenção da Licença Previa (LP), Licença de Instalação (LI), Licença & 76,28 \\
de Operação (LO) ou Licença Única de Instalação e Operação - LIO) & 73,72 \\
Quanto aos investimentos com estrutura física (edificação da agroindústria) & 73,72 \\
\hline Quanto a despesas com licenças, alvarás, certidões & 68,59 \\
Quanto a despesas com profissionais (responsável técnico) & 67,95 \\
Quanto a elaboração do projeto técnico, sanitário e ambiental & 66,67 \\
Quanto liberação/expedição de Certidão de uso/ocupação do solo expedida pelo município & 62,82 \\
Quanto ao registro dos produtos & 60,90 \\
Quanto ao Registro do Estabelecimento (em caso de agroindústria de produtos de origem animal e de & 59,62 \\
bebidas) ou Alvará de Funcionamento (agroindústrias de origem vegetal) & 55,13 \\
Quanto a rotulagem & 54,49 \\
Quanto a comercialização/escoamento da produção & 48,33 \\
Quanto à padronização do produto & 47,86 \\
Dificuldade para obtenção do Bloco de Produtor Rural & \\
Dificuldade quanto ao registro da empresa na Junta Comercial, e Cadastro Nacional de Pessoas & \\
Jurídicas (CNPJ) na Receita Federal &
\end{tabular}

\section{Resultados das perguntas abertas}

Abaixo, estão listadas as respostas dos donos de agroindústrias, quando questionados em relação a estas três perguntas abertas:

a. qual foi o maior entrave ou dificuldade no processo de legalização da sua agroindústria?

b. quais são as maiores dificuldades para manter a sua agroindústria em funcionamento?

c. c. quais as principais politicas e medidas de apoio devem ser implementadas para fomentar a legalização das agroindústrias? 
As questões abordadas a seguir foram elencadas de acordo com as respostas que mais se repetiram ao longo da avaliação dos questionários.

De acordo com os entrevistados, quando questionados nas perguntas abertas sobre qual foi considerada, em sua opinião, a maior dificuldade encontrada durante o processo de legalização, observou-se que a resposta que mais se repetiu entre os proprietários das agroindústrias locais, diz respeito à parte burocrática, uma vez que estes alegaram encontrar diversos entraves, tornando o processo de legalização lento e demorado. Algumas agroindústrias relataram a demora enfrentada na expedição de documentos referentes ao processo de legalização, que acarretou em uma longa espera para poder abrir a agroindústria, ou sair da informalidade. Também foi relatado, que apesar do grande empenho demonstrado pelos órgãos responsáveis, os proprietários das agroindústrias locais tiveram grande dificuldade em ter suas dúvidas sanadas em diversas etapas do processo de legalização. Outro ponto observado foi a falta de comunicação entre órgãos pelos quais tramitam os processos, 0 que ocasionou e corroborou para a demora no processo como um todo.

Em segundo lugar, foi citada a falta de incentivos financeiros por parte de programas do governo, no que diz respeito aos investimentos iniciais com infraestrutura adequada e equipamentos necessários. As agroindústrias questionadas descreveram como um grande entrave, a falta de recursos financeiros, uma vez que os investimentos despendidos para a construção da agroindústria são muito altos, o que fazia com que estas não conseguissem se legalizar, e permanecessem na informalidade.

Em terceiro lugar, foi mencionado sobre a grande dificuldade encontrada pelas agroindústrias em conseguir adequar-se as normas ambientais exigidas no momento da abertura da agroindústria, o que resultou em uma maior demora na liberação e expedição de alvarás e certidões referentes a esta etapa.

Em relação a segunda pergunta aberta, quando questionados sobre quais são consideradas as maiores dificuldades para manter as agroindústrias em funcionamento, a maior parte dos entrevistados citou a escassez de mão de obra qualificada para atuar no desenvolvimento e manipulação dos produtos, bem como a dificuldade em treinar os funcionários, para que estes entendam e apliquem as BPF (boas práticas de fabricação) a fim de produzir um produto final seguro e de qualidade para o consumo.

Segundo os proprietários das agroindústrias, outra grande dificuldade para manter as agroindústrias em funcionamento é a alta carga de impostos taxada sobre os mesmos, visto que vez que grande parte das agroindústrias entrevistadas enquadra-se em familiares ou empresariais de pequeno porte. Corroborando com isso, muitos entrevistados citaram a concorrência desleal que sofrem com as agroindústrias informáveis, uma vez que estas, por não necessitaram pagar os mesmos impostos, conseguem manter seus preços mais atrativos no mercado, dificultando que as agroindústrias formalizadas mantenham-se com preços concorrentes no mercado.

Em seguida, foi citado o alto custo despendido com análises físico-químicas e microbiológicas, sendo que estas análises obrigatórias são periódicas, devendo ser realizadas trimestralmente nos produtos e semestralmente na água que é utilizada no estabelecimento.

Outro ponto bastante discutido e de grande relevância, citado entre as maiores dificuldades para manter-se no mercado, é a obrigatoriedade das agroindústrias em possuírem profissionais responsáveis técnicos (RT), que são responsáveis por dar assessoria e atestar a qualidade da produção nas agroindústrias, bem como as representarem junto à fiscalização, dado que o custo para manter estes profissionais, é considerado relativamente alto, quando comparado proporcionalmente ao tamanho das agroindústrias em relação a sua produção. 
Algumas agroindústrias também comentaram sobre a dificuldade encontrada em manter-se em funcionamento, devido principalmente a grande concorrência com empresas alimentícias maiores, que logram grande parcela do mercado, pois possuem capacidades de produção e abastecimento maior, o que torna mais acessível a sua inserção nos grandes mercados consumidores. Neste mesmo sentindo, também foi abordado sobre as vantagens em relação aos custos de produção que as grandes empresas possuem, quando comparadas às pequenas agroindústrias locais, uma vez que por possuírem maior produção, conseguem diminuir seus custos com matéria prima e insumos, por exemplo, resultando em um produto final de menor preço, o que dificulta a competividade destas agroindústrias menores.

Também foi citado por algumas agroindústrias a dificuldade, principalmente financeira, em conseguir atender as demandas do órgão fiscalizador por constantes exigências a fim de atender a legislação vigente.

Ainda sobre as dificuldades em manter-se em funcionamento, algumas agroindústrias processadoras de carne e derivados, julgaram-se prejudicadas, pois as exigências legais aplicadas a estas, destoa consideravelmente quando comparada aos açougues, que por serem empresas que apenas adquirem a matéria prima (carne) e a comercializam sem processar, ou seja, sem transformar outros produtos derivados, como por exemplo, charque, linguiças e bifes empanados, tem uma cobrança mais branda do órgão fiscalizador competente.

Em relação a terceira e última pergunta aberta do questionário, quando indagados sobre possíveis sugestões de politicas públicas e ou medidas de apoio a serem implantadas por parte da administração pública, a fim de fomentar a legalização das agroindústrias, os entrevistados foram categóricos, sendo que a fala, que mais se repetiu diz respeito à desburocratização do processo de legalização. Grande parte das agroindústrias considera a desburocratização do processo de legalização como principal medida de apoio a ser adotada pelos órgãos públicos, pois muitos declararam considerar a lei vigente como principal objeto para demora do processo. Por esta razão a desburocratização, aparece como possível medida incentivadora na abertura de novas agroindústrias, bem como motivadora para tirar as agroindústrias informais da ilegalidade.

Em seguida, foi citado a necessidade de um maior apoio, incentivo e esclarecimento por parte dos órgãos públicos às agroindústrias que estão buscando a legalização ou às agroindústrias informais. Neste sentido, algumas agroindústrias sugeriram expandir os cursos e ou treinamentos de capacitação, assim como as palestras, com a intenção de zelar pela qualidade dos produtos desenvolvidos, como também salientar a importância da regulamentação das agroindústrias informais.

Outra resposta bastante presente em muitos questionários, diz respeito à necessidade que as agroindústrias percebem de atualização e ou criação de uma nova lei, voltada às agroindústrias de pequeno porte ou familiares. Conforme alegado por muitas agroindústrias, existe uma grande dificuldade de adequação nas normas da atual legislação, que acaba por inviabilizar o processo de legalização, pois faz com que as pequenas agroindústrias tenham de se enquadrar nas mesma legislação que é aplicada às indústrias alimentícias maiores.

Grande parte dos entrevistados, também sugeriu a criação de projetos que destinem recursos financeiros ou subsidiem a legalização de agroindústrias de pequeno porte ou que destinem recursos às agroindústrias familiares ou famílias de baixa renda as quais não possuem condições de viabilizar a formalização de suas agroindústrias.

Dentre as sugestões de medidas de apoio e/ou politicas públicas para fomentar a legalização das agroindústrias, observou-se também nos discursos a necessidade de criação de projetos que incentivem além da legalização, também a manutenção das agroindústrias, visto que muitas 
declararam possuir altos custos para manutenção e baixo capital de giro, o que levou a duas agroindústrias que participaram do estudo, a estarem com suas atividades paradas no momento da coleta dos dados. Também foi citado a possibilidade de incentivos como a isenção de taxas de alvarás e certidões para agroindústrias familiares.

Outras propostas encontradas nos discursos sugerem o subsídio para pagamento de responsáveis técnicos que atuam nas agroindústrias, ou a prestação deste serviço pelos próprios órgãos da administração pública, visto que muitas agroindústrias alegaram possuir dificuldades financeiras de arcar com este serviço. Também foi citado, a sugestão de criação de um único órgão, em que todas as informações e processos de legalização pudessem ser centralizados, a fim de facilitar o processo de abertura de novas agroindústrias.

Por fim, salientou-se a importância das universidades durante o processo de legalização, uma vez que estas possuem ferramentas capazes de auxiliar os produtores rurais e pequenos empresários, através, por exemplo, de projetos de extensão, que tenham por objetivo fomentar, esclarecer e capacitar os donos das agroindústrias.

\section{Considerações parciais}

Neste estudo, evidenciaram-se as dificuldades na legalização nos diferentes segmentos agroindustriais locais, retratando a realidade enfrentada em cada um deles. Com isso, observou-se que as agroindústrias processadoras de carne e derivados do município, apresentaram um alto grau de dificuldade, principalmente em relação à falta de legislação específica para agroindústrias familiares ou de pequeno porte do seu seguimento. O estudo também revelou que a burocracia enfrentada no momento da legalização, e também as etapas que compreendem o licenciamento ambiental (a obtenção da Licença Previa (LP), Licença de Instalação (LI), Licença de Operação (LO) ou Licença Única de Instalação e Operação (LIO), representaram algumas das maiores dificuldades desse setor. Em relação aos principais entraves enfrentados nas agroindústrias processadoras de leite e derivados, ficou claro que, assim como nas agroindústrias de carne e derivados, a maior dificuldade enfrentada foi também à falta de legislação específica para agroindústrias familiares ou de pequeno porte. A dificuldade na liberação/expedição de Certidão de uso/ocupação do solo expedida pelo município, seguido da burocracia enfrentada durante a formalização das suas atividades, também apareceu no topo da lista.

Em relação à agroindústria representante da categoria processadora de mel, o estudo revelou que as maiores dificuldades e entraves enfrentados, assim como nas demais categorias, dizem respeito à falta de legislação específica para agroindústrias familiares ou de pequeno porte e a parte burocrática. Nesta categoria, a rotulagem dos produtos também demonstrou ter sido bastante trabalhosa no momento da formalização.

O estudo também revelou diversas dificuldades para a manutenção das agroindústrias no mercado. Dentre elas, os proprietários apontaram alguns pontos, como por exemplo, a escassez da mão de obra qualificada, a dificuldade de treinamento dos funcionários, os altos impostos, a dificuldade de competir com agroindústrias informais, os altos custos das analises físico-químicas e microbiológicas dos produtos e da água, o alto custo para manter os responsáveis técnicos (RT), e, sobretudo, a grande dificuldade financeira para atender a legislação e as demandas dos órgãos fiscalizadores. 
Nesse sentido, entendemos a importância da legislação fiscal, sanitária e ambiental, e as normas exigidas pelos órgãos públicos durante o processo de legalização das agroindústrias. Porém, o presente trabalho corrobora com os demais estudos da área, em que se demonstram a importância da atualização da legislação vigente atual, principalmente em relação à necessidade de criação de leis direcionadas especialmente para as agroindústrias familiares ou de pequeno porte e a desburocratização do processo de legalização.

Por fim, enfatizamos a necessidade de criação de politicas publicas e medidas, que visem suprir a carência nas diversas etapas que compreendem desde o processo de legalização, até a permanência das agroindústrias no mercado. Para isto, salientamos a necessidade de criação de medidas simples, que vão desde o aumento da oferta de cursos de capacitação para garantir a qualidade dos alimentos, a promoção de palestras que demonstrem os benefícios da formalização das agroindústrias, até estratégias de ação mais elaboradas, onde haja a criação de projetos que facilitem o acesso ao crédito para construção ou reforma das instalações, bem como projetos de incentivos fiscais para agroindústrias de pequeno porte e familiares.

\section{Referências}

ABRAMOVAY R.; O capital social dos territórios: repensando o desenvolvimento rural. 2. ed. [S.I., s.n.], $2000 . \quad$ Disponível em: <http://empreende.org.br/pdf/Democracia\%20e\%20Participa\%C3\%A7\%C3\%A3o/O\%20capital\%20so cial\%20dos\%20territ\%C3\%B3rios\%20-\%20repensando\%200\%20desenvolvime.pdf>. Acesso em: nov 2016.

AMORIM, L. S. B.; STADUTO, J. A. R. Desenvolvimento territorial rural: a agroindústria familiar no oeste do Paraná. Rev. de Economia Agrícola, São Paulo jan./jun. 2008. 55v. 15-29p. Disponível em: < http://www.iea.sp.gov.br/ftpiea/publicar/REA1-0708a2.pdf >. Acesso em: nov 2016.

FERNANDES. D. M.; M.; ENGEL, B. S. Agroindústrias Familiares Rurais: vantagens e desvantagens da legalização. Redes. St. Cruz Sul, Online. Set./dez. 2016. 21v. 183-214p. Disponível em: < https://online.unisc.br/seer/index.php/redes/article/view/6904/pdf>. Acesso em: nov 2016.

GAZOLLA M.; Segurança alimentar e agroindústrias: políticas públicas e ações locais. Revista Segurança Alimentar e Nutricional, Campinas, 21v. n.2, $2014 . \quad$ 527-540p.

NICHELE, F. S.; WAQUIL, P. D; Agroindústria familiar rural, qualidade da produção artesanal e o enfoque da teoria das convenções. Cienc. Rural. Dez. Santa maria. 41v. n.12, 2011. Disponível em: $<$ http://www.scielo.br/scielo.php?script=sci_arttext\&pid=S0103-84782011001200030>. Acesso em: nov 2016.

PREZOTTO, L. L; Uma concepção de agroindústria rural de pequeno porte. Revista de Ciências Humanas EDUFSC. Florianópolis, v.31 133-153p, abr. 2002. Disponível em: <https://periodicos.ufsc.br/index.php/revistacfh/article/view/25195/22152>. Acesso em: nov 2016.

SACCO DOS ANJOS, F.; CALDAS. N. V.; OLIVEIRA. C.; Agroindústria familiar e políticas públicas no extremo sul do Brasil. Revista Desenvolvimento Socioeconômico em debate, 1v. 156-175p, 2015. Disponível em: <http://periodicos.unesc.net/RDSD/article/view/1834/1809>. Acesso em: nov 2016. 
SCARABELOT, M.; SCHNEIDER S. As cadeias agroalimentares curtas e desenvolvimento local - um estudo de caso no município de Nova Veneza/SC. Revista Faz Ciência, Unioeste. Paraná, jan./jun. 15v., n.20. 101-130p, 2012. Disponível em: <https://goo.gl/9NkA37 >. Acesso em: nov 2016.

SCHNEIDER, S. A abordagem territorial do desenvolvimento rural e suas articulações externas. Sociologias. Porto Alegre, jan./jun. 11v. 88-125p, $2004 . \quad$ Disponível em: $<$ http://www.scielo.br/pdf/soc/n11/n11a06.pdf>. Acesso em: nov 2016.

SULZBACHER, A.; DAVID, C. Agroindústria familiar rural: uma estratégia para melhorar a qualidade de vida no espaço rural. Geosul, Florianópolis, jan./jun. 24v., n.47. 69-90p, 2009. Disponível

em:

<https://periodicos.ufsc.br/index.php/geosul/article/view/2177-5230.2009v24n47p69/11704>. Acesso em: nov 2016. 